\title{
Toward a Science of History
}

\author{
Linda J. Parrott and Don F. Hake \\ West Virginia University
}

\begin{abstract}
The scientific status of History was compared to other sciences in the critical areas event selection, investigative operations, and theory construction. First, in terms of events studied, history is regarded as a quasi-scientific study of past events. However, viewed from the science of behavior's perspective of what historians actually do, history becomes a study of current records. As a study of currently existing records, not the non-existent past, history has potential to become a science. Second, like other scientists, historians may undertake manipulative investigations: they can locate the presence and absence of a condition in records and thereby determine its relation to other recorded phenomena. A limitation has been the lack of quantification that results from emphasis on the uniqueness of things rather than on their communality. Scientific training would facilitate viewing similar things as instances of a larger class that could be counted. Another limitation that cannot be easily overcome is the inability to produce raw data. This limitation has created problems in theoretical practices, the third area of comparison, because theoretical constructions have frequently been substituted for missing data. This problem too could be reduced through scientific training, particularly in other behavior sciences. An authentic science of history is possible.
\end{abstract}

\section{Traditional Views of Science and History}

To determine whether history may be included among the sciences requires a definition of "science" and a description of the historical enterprise, both of which are difficult to provide. A definition of "science" presents a problem because there really is no "science," only a large number of very different sciences, none of which may be considered the prototype. Moreover, the sciences and nonsciences are alike in that all human enterprises are concerned with the existence of things and the characteristics of those things that do exist (Kantor, 1953, p. 4).

Despite these difficulties, the sciences and the non-sciences have been differentiated on the basis of characteristics more common to one than to the other. Three aspects of an enterprise may be considered in making this determination. These aspects are: 1) the kind of things or events with which the enterprise is

We thank Rosalind Burns, Janis Buzzard, Cloyd Hyten, Jon Krapfl, and Ernie Vargas for their comments on an earlier draft of this paper. Reprints may be obtained from Linda J. Parrott, Department of Psychology, West Virginia University, Morgantown, WV 26506-6040. concerned; 2) the manner in which the work is carried out; and 3) the nature of the resulting products (i.e., descriptions, theories, laws, and so on).

With regard to the first of these aspects, science is held to deal with things and events that exist in space and time. "Things" not existing in these dimensions are considered to be non-existent from a scientific perspective, making further considerations of work with them, or the products of that work, unnecessary. The nature of the events isolated for study by a particular enterprise serves as a qualifying condition for admittance to the science category.

Given that this first condition is met, an enterprise is classified as more or less scientific on the basis of the last two aspects: the extent to which the work may be regarded as rigorous and methodical and whether the products of that work may be regarded as novel and useful. The existence of a category of "social sciences," as contrasted with "basic sciences," testifies to the difficulties that have been encountered in attempting to establish mutually exclusive categories of "science" and "nonscience" and suggests that the compromise has been a continuum.

We may examine the historical enter- 
prise using these same criteria. In doing so we are faced with a number of problems, the first being how to conceptualize the subject matter of historical study. It is usually argued that history deals with things of the past - things which did exist but which no longer exist (J. T. Shotwell, 1964, p. 126; G. K. Clark, 1967, p. 1; J. R. Kantor, 1981, p. 317; Meiland, 1965, p. 190). The question becomes: Do nolonger-existing things constitute existing or nonexisting things? Whether or not history ought to be excluded from the scientific domain on this issue alone is a matter of debate.

Second, regardless of the position taken on the first issue, most would agree that no-longer-existing things must be handled in unusual ways (Clark, 1967, p. 25; Shafer, 1980; Cuneo, 1963, pp. 206230; Todd, 1972, pp. 161-181; Rouse, 1972, pp. 86-113). That is, the work of the historian is necessarily unlike that of the more typical scientist. Specifically, what appears to be completely absent in the historical enterprise is the experimental method-the means by which the effect of one variable on another may be satisfactorily assessed by controlling extraneous variables and manipulating independent variables. Missing is the means by which causal knowledge may be obtained, as noted by the historian, G. K. Clark:

Since the problem of what causes war is of greatest importance to humanity it would be very desirable to determine which of all [possible] factors were the operative ones without which war would not have happened. But it cannot be done. An historian cannot do what a scientist might do, that is repeat the whole process after having abstracted one, or more, of the factors to see whether the result in each case would be the same. $(1967$, pp. 22-23)

Moreover, should the certainty of our knowledge of no-longer-existing events become suspect, there exists no means by which it may be confirmed (Croce, 1960, p. 51; Salmon, 1929, p. 9; Maritain, 1973, pp. 6-8). Hence, we are unable to have the same degree of confidence in historical knowledge as we may have in knowledge for which confirmation-by-replication procedures are applicable.

Finally, the products of historical study are also adversely affected by the nature of the events studied. If there are no procedures by which to obtain causal knowledge about such events, causal knowledge does not emerge as a product of historical study. What does emerge is a description of no-longer-existing events arranged in chronological order. ${ }^{1}$ This is not to suggest that the discovery and illumination of temporal relations among events is not useful. However, time is a measure of change, not the cause of it.

In summary, the principal difference between history and science is the nature of the things and events investigated, from which follows differences in procedures and products. Standard scientific procedures are not applicable to no-longer-existing events, the result being that the products of historical investigations are of questionable scientific value. In short, so long as history is the study of no-longer-existing events, it will be excluded from the domain of the sciences.

This exclusion meets with acceptance by numerous historians who regard history as more akin to poetry, literature, or metaphysics than to science, among them: C. A. Beard (1939, pp. 219-229); T. Carlyle (cited in Kantor, 1981, p. 320); E. H. Clarendon (cited in Kantor, 1981, p. 320); Dray (1966); G. W. F. Hegal (1944); H. S. Hughes (1964, pp. 1-21); T. B. Macaulay (cited in Beatty, 1938, pp. 307316); L. B. Namier, 1957, pp. 371, 386); Jacques Maritain (1973, pp. 170-176); E.

\footnotetext{
${ }^{1}$ Some controversy exists as to whether or not a chronicle of this sort is synonymous with history (Croce, 1960; Atkinson, 1978). Philological historians contend that history comprises merely the compiling of documents (Meiland, 1965, pp. 2425 ), and they have been criticized for assembling the dead materials of the past instead of emphasizing their role in the understanding of new historical problems (Holborn, 1972, p. 17). Deterministic and teleological histories also begin with what Croce calls "brute facts," coupled with attempts to link them together in linear causal sequences toward some final goal in the latter case. Most historians place significantly greater emphasis on the interpretative phases of history, however, some going so far as to suggest that the events of history are merely the creations of historians, as noted by Kantor (1981, pp. 320-321).
} 
Meyer (cited in A. L. Rouse, 1946, p. 92); J. T. Shotwell (1964, pp. 85-87); G. M. Trevelyan $(1949$, p. 52); and E. Gibbon (cited in J. B. Black, 1926). Their arguments differ, of course, but certain assumptions appear to be shared by all. Specifically, because historical works are the creations of individual historians with unique experiences and interests, historical knowledge is regarded as necessarily subjective and individual. Consequently, inasmuch as science is concerned with objectivity and generality, there can be no science of history.

Others (Fustel de Coulanges, 1957, p. 178; J. B. Bury, 1930, pp. 3-22; R. G. Collingwood, 1946, p. 9; York Powell, cited in A. L. Rouse, 1946, pp. 86-87; E. Cuneo, 1963; pp. 206-230; W. Todd, 1972) take issue with this view, arguing that history is, or at least should be, a science. In Collingwood's words: "Science is finding things out; and in that sense history is a science." Assertions of a similar sort attributed to Bury and to de Coulanges, are frequently cited in support of this position (for example, see Kantor, 1981, p. 320; or Rouse, 1972, p. 92). Despite their assertions, some rather unorthodox methods are to be found in the scientific programs proposed by these historians. For example, Collingwood proposes a procedure that has come to be known as sympathetic identification with historical figures. The procedure involves imagining oneself to be the historical figures about which one seeks knowledge, the purpose being to experience the motivational circumstances attending these figures. By means of such imaginary experiences, the causes of historical figures' actions are thought to be revealed to the historian, who is then in an advantaged position to explain the events of the past (Todd, 1972, pp. 161162).

While it is no doubt true that historians must engage in constructional operations, as must any scientist, histories based on the sort of free imagination proposed by Collingwood partakes more of the quality of literature than of science. Hence, to whatever extent practices of this type characterize the historical en- terprise, it must be concluded that history falls outside of the scientific domain.

\section{Nontraditional Views of \\ History and Science}

These views of history and science fail to do justice to either discipline. Viewed from the psychological perspective of what historians actually do, history and science may not be differentiated on the basis of the type of event investigated. To be eliminated here is the suggestion that historians study no-longer-existing events. The subject matter of historical investigation is not events of the past but, is, instead, currently existing products or records of alleged past events. The historian studies De Anima, not Aristotle and his activities, just as the psychoanalyst studies current tales of the past, not the past itself.

Croce $(1960$, p. 51$)$ takes this view, arguing that it is not the relation between records and past events that constitute the subject matter of history, but rather the relation between records and historians' interactions with them. As Meiland $(1965$, p. 14) points out, it is only the latter relation that can answer to scepticism. Croce's theory of history is not in keeping with the formulation of history as a natural science to follow, however, as it is based on a type of idealistic philosophy in which historians are regarded as contributors to the things and events with which they interact. That is, , history is held to be "produced" or "created" in the interaction of the historian with available records. It is not regarded as a process of discovery (Croce, 1960, pp. 12, 75; Meiland, 1965, pp. 18-22).

Likewise, Oakeshott (1933, chapter 3) argues that history is not concerned with the past, but not because knowledge of such events cannot be verified, as in Croce's case. On the contrary, history is not concerned with events of the past because there are no such events with which to be concerned. In other words, only those things exist with which we have experience, and since we cannot experience the past, it does not exist. Like Croce, Oakeshott adheres to a constructionist 
theory of history, and like all idealistic theoreticians, he fails to distinguish between objects and actions with respect to them (Kantor, 1945, p. 208). In short, beyond Croce's and Oakeshott's rejection of the past as the proper subject matter of historical study, their views depart radically and fundamentally from course of analysis to follow, and for this reason they will not be considered further.

Returning, then, to the argument that the subject matter of history is not the past but currently existing records of alleged past events, we may anticipate certain legitimate objections to this view. For example, it might be argued that such records refer to past events and it is only because they do that they are of any interest at all, the implication being that while the record is the datum of necessity, the past is the datum of interest. In other words, the no-longer-existing past does indeed constitute the subject matter of historical studies. We may agree that the no-longer-existing past makes a fascinating story for which people have always shown an interest. However, such interest is not properly regarded as "scientific," because no-longer-existing events do not lend themselves to scientific investigation. From a scientific perspective, on the other hand, it is the record that is studied, and there is no more reason to regard the record as a substitute for the past than there is to regard the child as a substitute for the parents. The past, or at least some aspects of it, exist in the record just as do some aspects of the parents exist in the child. However, the record, like the child, may be regarded as an autonymous entity worthy of study in its own right.

Even if it is conceded that historians do study currently existing phenomena, the argument may still be made that records - as data - are unlike the pristine or original things and events studied in the other sciences. Hence, if history cannot be excluded from the domain of the sciences on the grounds that its data are nonexistent, it can still be refused admittance to the basic sciences because it does not study the original phenomena. However, the study of records such as occurs in history is not unlike that prevailing in numerous other so-called basic and social sciences, among them historical geology, paleontology, archeology, and anthropology. Nor even is the study of records peculiar to sciences with so obvious an historical orientation. Consider the astronomer's study of light from no-longer-existing stars, and the physicist's study of traces left by rapidly spinning particles in a cyclatron. The only difference between these sciences and those like history and linguistics is that the records in the latter cases consist primarily of verbal materials.

In summary, history cannot be denied scientific status on the grounds that its data are nonexistent, nor can it be argued that the data of historical studies are any less basic than those of the other sciences. Nonetheless, this status has been denied history, and there may have been practical reasons for this denial. Specifically, because history has not traditionally been aligned with the sciences, its methods of investigation and theory construction have not evolved in the same way as have the methods of more typical sciences; nor have historical products been put to the same tests of usefulness as their scientific counterparts. That is, historians and scientists do not operate according to the same rules, nor do they strive to the same ends. In fact, history and sciences have been regarded as so radically different that they are often not even thought to complement one another (Namier, 1957; Dray, 1966; Trevor-Roper, 1957).

Keeping in mind, however, that the science-nonscience dichotomy may be described as a continuum of investigative rigor and product utility, the fact that history has not had a scientific past does not prevent it from having a scientific future. All that may be required for history to realize its scientific potential are modifications in its procedures and products. In fact, because the nature and value of products are, to such a large extent, determined by the procedures from which they are derived, the assignment becomes clear: History can become scientific to the extent that its investigative 
and constructional practices approximate those of the basic sciences.

Precisely how much change in these practices is necessary depends, of course, on how closely current historical methods approximate those of the so-called basic sciences. To make this determination, the investigative and theory construction practices of history will be compared with those of other sciences, particularly other sciences that, like history, focus on human behavior.

\section{A Comparison of Historical and Behavioral Methodologies}

Three aspects of methodology will be addressed: Event selection, investigating operations, and theory construction.

Event selection. Event selection refers to the things or events isolated as the subject matter of a particular science, as well as how that subject matter is analyzed into units. With regard to the isolation of a subject matter, history and the science of behavior appear to have selected different kinds of phenomena for study. The primary data of historical studies are things - static objects with definite substantive structure. Historians study records, not the making of them. Behavioral data, on the other hand, are constituted of events-fluid actions of things, or relations among them, that do not have substantive structure. Behavioral scientists study functional relations among responses and stimuli, not responding organisms and stimulating environments. The latter are the subject matters of biology and physics, not the science of behavior.

At least this is how it appears at first glance. Actually, events are too illusive to deal with directly - they must be transformed into things to be investigated. Hence, the fluid acts of organisms are converted into static records of their effects on the environment. That is, behavioral scientists study cumulative records, digital displays, videotapes, etc. By this reasoning, it may be concluded that behavior scientists and historians do not differ with respect to the phenomena isolated for study by each. Both study rec- ords of events - things - rather than the events themselves.

History and behavior science do differ on this issue in one important respect. While both study records, records are the raw data of historical studies; which is to say, historians can collect these data but they cannot produce them. The production of the raw data for historical studies took place at another time through the efforts of other workers. On the other hand, the records studied by behavioral scientists are not their raw data, but are, rather, contrivances produced by these same workers in an effort to overcome the difficulties involved in the study of fleeting events. As such, the data set of the behavior scientist may be enlarged at will.

The limited data set of the historian presents a serious problem, namely, missing data cannot be produced. Hence, there is a greater tendency for theoretical constructions to be incorporated in what are normally regarded as the descriptive phases of scientific work. As a result there is considerable danger of confusing theoretical constructions with descriptions of observed things (Fogel \& Engerman, 1974 , pp. 4-5). The problem here is that while descriptions of things are controlled by features of those things, constructions tend to conform to cultural tradition-and often not the tradition prevalent at the time of the events constructed, but of the historian in the current frame of reference. Consequently, what historians construct about the past may bear very little resemblance to the past. In this context, Clark makes a valuable suggestion:

[It] must always be remembered that history is after all the reflection of a man or woman working at a point in time on what happened at another point in time, and considering the result, the date at which the history is being written is as much to be taken into account as the date of the events which are being written about. $(1967$, p. 37)

Another difference between the science of behavior and history concerns the manner in which each partitions its subject matter into units. In fact, it is on this issue that the two disciplines appear to differ the most. A common unit of anal- 
ysis for the behavioral scientist is the operant $-\mathrm{a}$ class of responses occurring under the same antecedent conditions and producing the same consequences (see Skinner, 1969, pp. 127-132, for a discussion). For example, under the antecedent conditions of a closed door, a number of topographically different responses will be effective in producing the consequence of an open doorway (e.g., ringing the doorbell, knocking on the door, calling out for someone to open the door, breaking down the door). All of these responses, because they occur under the same antecedent conditions and produce the same consequences, may be considered members of a single operant class. The significance of the concept of the operant is that it allows even very different events-from a topographical standpoint - to be regarded as instances of a single phenomenon. As such, instances may be counted, and from these operations the probability that a given bit of behavior will occur at a given time may be calculated. The operant, then, by subordinating the uniqueness of events to the similarities among them makes possible the application of mathematical methods to behavioral scientists' subject matter.

Similarly, units of analysis have been abstracted from the records constituting historical data. These include personal careers ("great men"), technological or philosophical developments (i.e., histories organized in accordance with important inventions or ideas), wars or other outstanding events of a natural or cultural sort, as well as "ages" or periods of time. However, historians have not ordinarily approached their subject matter with quantification as a goal. Consequently little if any attempt has been made to employ standard units of measure. ${ }^{2}$ As

\footnotetext{
${ }^{2}$ The application of mathematical and statistical methods to economic history, known as "econometric history" (Conrad and Meyer, 1958), or "cliometrics," is not an exception. The strategy employed by historians of this persuasion involves a thorough search for numerical records coupled with an attempt to use mathematical procedures to construct missing data. The issue at hand, however, is the abstraction of units of analysis from records
}

a result, the similarities among eventsor their records-tend to be ignored in favor of their differences. It is the uniqueness of an event that ensures it a place in the narrative of history.

Some controversy exists as to whether or not generalizations about historical situations are legitimate - in our terms, whether or not it is possible to predict occurrences on the basis of similar occurrences. At one extreme are the universalists (for example, Hegel) who regard history as the unfolding of some predetermined plan. When the course of historical events is formulated at this level of abstraction, the concrete events of history lose their distinctive character, and the problem of generalizability among them is sidestepped. At the other extreme (for example, Trevelyan) are those who defend the absolute uniqueness of historical situations, owing to the inordinate complexity of such situations and the facts of their continuous evolution. Moreover, when human history is at issue, the uniqueness of the individual emerges as an additional impediment to generalization, according to this view. An intermediate position is taken by Clark (1967) and Rouse (1946, p. 17). Clark argues that if it were not possible to generalize from one event to another, history would have little interest and no significance. He concludes that the very writing of history suggests some generalization is possible, although he warns against the oversimplification of events for this purpose. We sympathize with Clark's position on this issue, as it is only on the basis of some generality among historical events that a science of history may proceed.

Investigating operations. Scientific investigation constitutes observation, manipulation, and transformation of existing phenomena for the purpose of ascertaining their nature, occurrence, quantity, origins, and relations with other phenomena (Kantor, 1953, pp. 115117).

that may, in turn, be counted or otherwise operated upon mathematically. In this way, things heretofore not counted can be quantified for the purpose of predicting similar occurrences. 
Although observation, manipulation, and transformation may be conceptualized as a continuum (Kantor, 1953, p. 103), it is by virtue of their differences that a comparison of history and the science of behavior may be accomplished. We may begin this comparison with an examination of the ability of each to make observations. When the data of historical study are properly regarded as records of alleged events, rather than the events themselves, it becomes clear that the historian suffers no disadvantage with respect to observation. In fact, in as much as historical data are static things as opposed to fleeting events, the historian may be in an even better position than the behavioral scientist in this regard. However, as previously discussed, the behavioral scientist overcomes the difficulty of dealing with fleeting events by first transforming them into things.

To a large extent, history is an observational science. That is, investigation consists of observing records concerning their nature, quantity, occurrence, and copresence with other records. Many sciences are of a similar sort. The problems of astronomy, for example, do not lend themselves to manipulative methodologies and must be solved by other means. For the most part, observational methods are employed, resulting in records of the position and movement of the stars and planets over extended periods of time. Field studies of this sort are not uncommon in the science of behavior as well, particularly in the early phases of investigative activity.

Turning to the manipulative aspects of investigation, history and behavior science appear quite different. In fact, one of the main reasons for refusing history scientific status concerns differences in the ability of each to conduct manipulative investigations (Clark, 1967, p. 22). Historical study does not end with the arrangement of crude records in chronological order, however. Records can be analyzed and reanalayzed, organized and reorganized until similarities and differences among them are discovered. Investigation of this sort is not unlike the manipulative investigations conducted by the behavioral scientist. For example, in the study of conditioned suppression, the effect of introducing a conditioned aversive stimulus in the context of ongoing, food-maintained behavior is assessed. The experiment here consists of presenting and withdrawing a stimulus while observing correlated changes in operant behavior. A similar kind of experiment could be performed by a historian.

For instance, as mentioned earlier, ideas constitute units of analysis in history, similar to the operant in the science of behavior. One such unit is the concept of psychophysical dualism. This idea has a certain prevalence or strength, which may be detected by observation or scrutiny of records of psychological thought throughout history. The relationship between this idea and some other variable, such as the stability of social conditions, might be investigated by examining the prevalence of psychophysical dualism under stable and unstable social conditions. Essentially, the historian examines the strength of this unit as social context changes from stable to unstable, just as the behavior scientist examines the strength of the food-maintained operant as the setting changes from one in which aversive stimuli are present to one in which they are absent. Changes in the strength of the food-maintained operant under these conditions are regarded as a discovery. Likewise, if it is found that dualistic ideas and institutions flourish during periods characterized by unstable social conditions, and wane during periods of stability, then a discovery has been made in the science of history. Further, this discovery might be used to predict the occurrence of such ideas in future records.

It might still be argued, however, that the manipulative activities of the historian and behavioral scientist differ in the sense that the behavior scientist actually produces changes in the events under investigation, while the historian merely identifies changes that have occurred for other reasons. It is not possible, of course, for the historian to produce changes in the social conditions of previous times and observe the effects of such manipu- 
lations on the prevalence of dualism at those times. Given that this is the case, the argument could be made that no manipulation of variables has, in fact, occurred. However, we must keep in mind the fact that the historian's data are records of past events, not the past events themselves, and whatever manipulation of variables takes place must take place at the level of the record. At this level, examining the occurrence of one event in the presence and absence of some other event constitutes the historian's manipulation of a variable. The main problem facing the historian in this regard arisesagain - from the fact that the raw data of history cannot be produced at will. As a result, the number of replication opportunities is fixed and may be too small to allow for believable relations among variables to be established. Nonetheless, history does repeat itself, as the saying goes, and some number of replications are likely to be possible. Hence, while the possibilities for manipulative experimentation in history are limited, they are not absent altogether. Neither, then, is the possibility for discovery.

Discovery is also possible by means of transformation procedures, which are common in both history and the science of behavior. In the science of behavior, event records are transformed into other kinds of records by way of mathematical procedures, with the result that new relations among events (or a least event records) are discovered. For example, the relationship between rates of responding and rates of reinforcement in a multipleoperant situation is clarified by converting absolute measures of responding and reinforcement for each response into their relative equivalents and expressing the resulting ratio values in the form of an equation. By this procedure it has been discovered that relative response rates for two responses approximately equal relative reinforcement rates of the two responses (Herrnstein, 1970). Other common transformations include discrimination and suppression ratios, in which responding during one stimulus is considered relative to another.

Similar transformations may take place in the course of historical investigations. However, in history transformations rarely involve numerical conversions. Instead, one set of terms describing a concept or set of circumstances is converted into another set of terms that has essentially the same meaning. By this procedure, seemingly disparate events may be shown to be quite similar, with the result that accumulated knowledge pertaining to one event may be applied to the understanding of another and vice versa.

We recently conducted an informal transformation of this sort in the context of psychological history using Elliot Hearst's (1979) edited book, "The First Century of Experimental Psychology," in which different authors describe the history of the major areas of experimental psychology. Examination of the chapters on motivation (Brown, 1979), animal learning (Jenkins, 1979), and psychopathology (Maher \& Maher, 1979), revealed that an essential aspect of conditioned suppression - the disruption of ongoing behavior during a conditioned stimulus-was known in these areas by different names, among them: conditioned suppression, conditioned anxiety, learned helplessness, operant-respondent interactions, conditioned fear, acquired drives, and experimental neurosis. When all of these phenomena were viewed as "disruptions of ongoing behavior," the conceptual formulations and empirical evidence originally acquired with respect to each of the similar phenomena suddenly became relevant to the analysis, understanding, and historical context of conditioned suppression. The outcome was to increase what we knew about the phenomena of conditioned suppression-as well as all of the similar phenomena to which it is related.

In history, transformations of this type involve converting such items as "national security" into "economic advantage," "religious conflict" into conflicts involving resources of a more tangible sort, and so on. From these conversions, complex and seemingly dissimilar circumstances may be simplified, compared, and understood in relation to oth- 
er copresent aspects of records. The book "Time on the Cross" by Fogel and Engerman (1974), which discusses the relation between the moral and economic indictments of slavery, is a good example of this strategy.

Theory construction. Theory construction refers to abstracting and generalizing activities that result in verbal products or constructs called laws or principles. Laws are statements of order, regularity, or interrelation of observed factors. Collections of laws organized in accordance with a set of underlying presuppositions or postulates are called theories.

Scientific laws are formulated on the basis of observed things and events and, as such, do not ordinarily contain reference to factors not actually present in the observations of those things and events. For this reason, scientific laws are regarded as continuous with the raw data upon which they are constructed (Kantor, 1953 , p. 33).

There is nothing to prevent the historian from operating according to these same rules. Unfortunately, however, historians have not often been trained as scientists, and their constructional practices have evolved in accordance with other traditions and in keeping with other goals. As discussed earlier, history is a record of unique events, which is to say that historians have traditionally exploited the differences among phenomena as opposed to their similarities. Generalizing and abstracting operations, by which laws and principles are derived, proceed by identifying similarities among phenomena, however. Consequently, laws and principles that might be considered continuous with raw data are almost completely lacking in historical treatises (although see Cuneo, 1963, for a somewhat questionable attempt to formulate such laws). Instead, more elaborate theories are constructed on a framework of laws borrowed from other sciences.

History is not alone in this regard. The practices of theory construction in many sciences are far less sophisticated than their investigative practices. However, the fact that a limited number of available records constitute the raw data of his- torical studies exacerbates the problem. Specifically, because raw data are incomplete, continuity must be accomplished by means of interpretation and presupposition. Hence, while inadequate constructional practices in other sciences may be ignored in the wake of vigorous data production, these inadequacies become even more obvious as historians proceed with their investigations.

\section{Conclusions}

The problem with historical studies, then, is not that they cannot be scientific in nature, but that they are not as scientific as they could be. Several steps may be taken to facilitate the development of a science of history. The first concerns the training of historians. Were historians trained as scientists, they would be more alert to the differences between observations and the constructions derived from them, with the result that practices of theory construction would be more carefully regulated. A specific outcome of such training could be to minimize the influence of cultural tradition and personal idiosyncracy on historical treatises. Scientific training would also alert historians to the nature of useful records, that is, records containing not only what occurred but, to whatever extent possible, the circumstances under which it occurred. For example, the influence of a "great man" of history, as well as his appearance at a particular time, may be more readily understood if his achievements are described in the context of other ongoing events and circumstances available in other records of the same period. Likewise, the development and influence of a particular bit of technology-such as the printing press - may be more readily understood and appreciated if described in the context of other technological, economic, political and military circumstances (Clark, 1967, p. 25). Finally, scientific training would encourage historians to evaluate their hypotheses and speculations. For example, a hypothesis concerning the circumstances responsible for the French Revolution might be confirmed, or at least rendered 
more believable, if similar social upheavals were also potentially attributable to these same circumstances. Hypotheses with respect to one set of records might also be evaluated by the extent to which they are consistent with related sets of records and other hypotheses, a point made by Croce (1960).

The emergence of an authentic science of history will no doubt depend on more than these alterations in the training of historians. The audience or consumers of history must undergo a similar change if the scientific practices of historians are to be maintained. Specifically, consumers must be prepared to evaluate the accomplishments of historians; they must be able to distinguish a valuable treatise from one of little or unknown value. Particularly important in this regard is a recognition of the fact that a historian's account is necessarily influenced by his or her personal and cultural experience, which is to say, bias is never completely eliminated. This fact does not preclude the possibility of an objective evaluation of historical treatises, however. On the contrary, it establishes criteria for making such an evaluation. Specifically, because bias is inevitable, responsible consumers must undertake the task of detecting a particular historian's bias from which standpoint his or her treatise may be more fully understood. This task becomes virtually impossible, however, when the primary data for a treatise consist of treatises of other historians because under these circumstances the assumptions and postulates of each contributor are included and combined without acknowledgement or possibility of detection. Consequently, the value of a historical treatise is determined, at least in part, by the ratio of primary to secondary sources constituting the data upon which it is based, and by whether or not the historian has stated his/her assumptions. $^{3}$

\footnotetext{
${ }^{3}$ A good example of a valuable treatise is Kantor's The Scientific Evolution of Psychology (1963, 1969), a history of psychology beginning with the Ancient Greeks. All sources are primary, and references are given in the languages of the original writers. Herrnstein and Boring's "A Source Book
}

Finally, a science of history depends on the availability of records as data, which in turn depends on the making of records in the ongoing process of scientific activity. Hence, to the extent that records of sufficient quantity and quality are made, their history - to be discussed at some later time-will be more complete. However, the making of records is not properly regarded as the work of the historian. The historian is one who operates on records produced by other workers at other times.

\section{Why a Science of History}

The benefits of historical studies and how these might be multiplied with the development of an authentic science of history remain to be addressed. The benefits that would accrue with the development of a science of history are presumably not unlike those associated with the development of any science. Namely, the extent to which we regard our knowledge of a particular subject matter as scientific is the extent to which we have confidence in that knowledge and are thereby prepared to operate on the basis of it. In other words, knowledge of events alters our subsequent reactions to similar events, the result being that successful interactions with that particular sort of event are facilitated.

In addition to these very general sorts of benefits, history is a a unique discipline with a unique contribution to make. While other sciences undertake the study of particular sets of events, concentrating on their present states and immediate changes, history investigates the origin and development of any set of events which allegedly occurred at some previous time. In a sense, then, history is a thoroughly interdisciplinary science: it is the science of early phases of other sciences. The significance of this feature of the historical enterprise is that interdis-

in the History of Psychology" (1966) is another example, however, in this book inscrutable biases are minimized by another procedure: primary sources are included as text. The outcome is to allow readers to replace the historians' bias with their own. 
ciplinary knowledge of things and events is more complete than knowledge of these same phenomena from the standpoint of a single discipline. In other words, the more we know about the origin and development of a particular event (i.e., its history), the more we may expect to understand about its present states and immediate changes. Hence, any advancement of the science of history may be regarded as an advancement of other sciences as well. This is particularly true of sciences that have an organic subject matter, such as biology or behavior science.

Moreover, some phenomena can be understood only from the perspective of history and, as a result, a good deal of scientific work is directed at recovering the processes by which present things and events have become what they are. For example, we classify a stimulus as a reinforcer for a particular organism only if we know that it has followed some behavior in the past, and there has occurred subsequently an increase in the frequency of that behavior. In fact, when events constitute the data of interest, because they lack substantive structure a knowledge of their origin and development may be the only means of differentiating one from the other (e.g., Kantor, 1938; Skinner, 1953). The point is that all events are historical; they are phases of other events.

In conclusion, knowledge of the past is a critical component of our understanding of the present, which is to say, it is an aspect of the present about which we seek knowledge and knowledge is acquired under scientific auspices. Hence, a science of history is inevitable; it follows naturally from an appreciation of the fact that the past is a current phenomenon.

\section{REFERENCES}

Atkinson, R. F. Knowledge and explanations in history: An introduction to the philosophy of history. Ithaca: Cornell, 1978.

Beard, C. A. Written history as an act of faith. American Historical Review. 1939, 2, 219-229.

Beatty, R. C. Macaulay. Norman, Oklahoma: University of Oklahoma Press, 1938.
Black, J. B. The art of history. London: Methuen \& Co. Ltd., 1926.

Brown, J. S. Motivation. In E. Hearst (Ed.), The first century of experimental psychology. Hillsdale, NJ: Lawrence Erlbaum Associates, 1979.

Bury, J. B. The science of history. In Selected essays. Cambridge: Cambridge University Press, 1930.

Clark, G. Kitson. The critical historian. New York: Basic Books, 1967.

Collingwood, R. G. The idea of history. Oxford: Oxford University Press, 1946.

Conrad, A. H., \& Meyer, J. R. The economics of slavery in the ante bellum south. Journal of Political Economy, 1958, 66, 95-130.

Croce, Beneditto. History: Its theory and practice. NY: Russell \& Russell, Inc., 1960.

Cuneo, Ernest. Science and history. New York: Duell, Bloan and Pearce, 1963.

de Coulanges, Fustel. An inaugural lecture. In F. Stearn (Ed.), The varieties of history. New York: Meridian, 1957.

Dray, W. H. (Ed.). Philosophical analysis and history. New York: Harper \& Row, 1966.

Fogel, R. W., \& Engermann, S. L. Time on the cross: The economics of American negro slavery and evidence and methods-a supplement. Boston and Toronto: Little, Brown and Co., 1974.

Hearst, E. (Ed.). The first century of experimental psychology. Hillsdale, NJ: Lawrence Erlbaum Associates, 1979.

Hegal, G. W. H. [The philosophy of history] (J. Sibree, trans.). NY: Wiley, 1944.

Herrnstein, R. J. On the law of effect. Journal of the Experimental Analysis of Behavior, 1970, 13, 243-266.

Herrnstein, R. J., \& Boring, E. G. (Eds.), A source book in the history of psychology. Cambridge: Harvard University Press, 1966.

Holborn, Hajo. History and the humanities. NY: Doubleday \& Company, 1972.

Hughes, H. S. History as art and as science. NY: Harper \& Row Publishers, 1964.

Jenkins, H. M. Animal learning and behavior theory. In E. Hearst (Ed.), The first century of experimental psychology. Hillsdale, $\mathrm{NJ}$ : Lawrence Erlbaum Associates, 1979.

Kantor, J. R. The nature of psychology as a natural science. Acta Psychologia, 1953.

Kantor, J. R. Psychology and logic (Vol. 1). Chicago: The Principia Press, 1945.

Kantor, J. R. The logic of modern science. Chicago: The Principia Press, 1953.

Kantor, J. R. The nature of psychology as a natural science. Acta Psychologica, 1938, 4, 1-61.

Kantor, J. R. The scientific evolution of psychology (Vol. 1). Chicago: The Principia Press, 1963.

Kantor, J. R. The scientific evolution of psychology (Vol. II). Chicago: The Principia Press, 1969.

Kantor, J. R. Interbehavioral philosophy. Chicago: The Principia Press, 1981.

Maher, B. A., \& Maher, W. B. Psychopathology. In E. Hearst (Ed.), The first century of experimental psychology. Hillsdale, NJ: Lawrence Erlbaum Associates, 1979.

Maritain, Jacques. On the philosophy of history. Clifton, NJ: Augustus M. Kelley Publishers, 1973. 
Meiland, Jack W. Sceptism and historical knowledge. New York: Random House, 1965.

Namier, L. B. History and political culture. In F. Stern (Ed.), The varieties of history. New York: Meridian, 1957.

Oakeshott, Michael. Experience and its modes. Cambridge: Cambridge University Press, 1933.

Rouse, A. L. The use of history. London: Hodder \& Staughton Limited, 1946.

Rouse, I. Introduction to prehistory: A systematic approach. New York: McGraw-Hill Book Co., 1972.

Salmon, Lucy Maynard. Why is history rewritten? New York: Oxford University Press, 1929.

Shafer, R. J. A guide to historical method. Homewood, IL.: Dorsey Press, 1980.
Shotwell, James T. The faith of an historian and other essays. NY: Walker and Company, 1964.

Skinner, B. F. Science and human behavior. New York: Macmillan, 1953.

Skinner, B. F. Contingencies of reinforcement: $A$ theoretical analysis. New York: Appleton-Century Crofts, 1969.

Todd, William. History as applied science. Detroit: Wayne State University Press, 1972.

Trevelyan, G. M. An autobiography and other essays. New York: Longmans, Green and Co., Ltd., 1949.

Trevor-Roper, H. Historical essays. London: Macmillan, 1957. 